\title{
Cyclospora cayetanensis
}

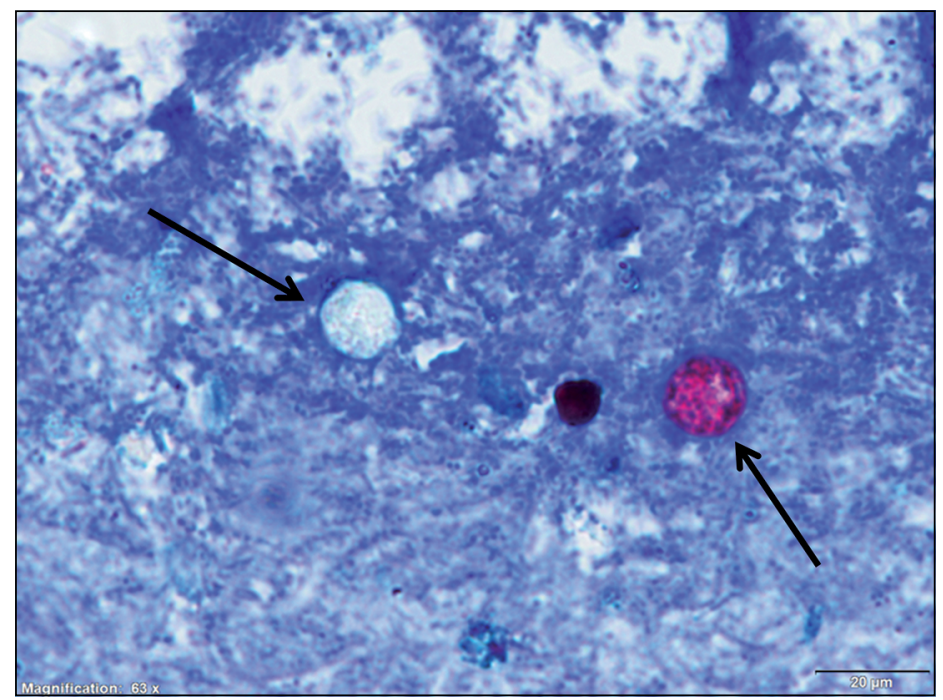

Figura 1. Ooquistes inmaduros en heces con tinción de Kinyoun (algunos se tiñen rojos, otros pierden la tinción).

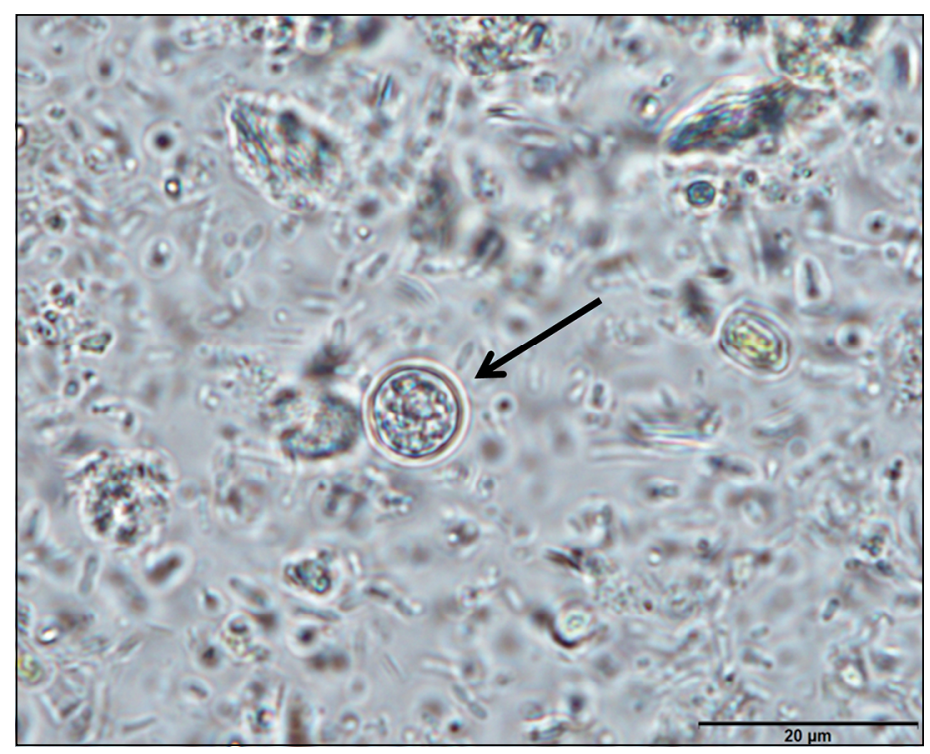

Figura 2. Imagen típica de ooquiste inmaduro en examen de heces al fresco: "pelota de golf" (forma redonda, 8-10 $\mu$ m de diámetro, refringente).

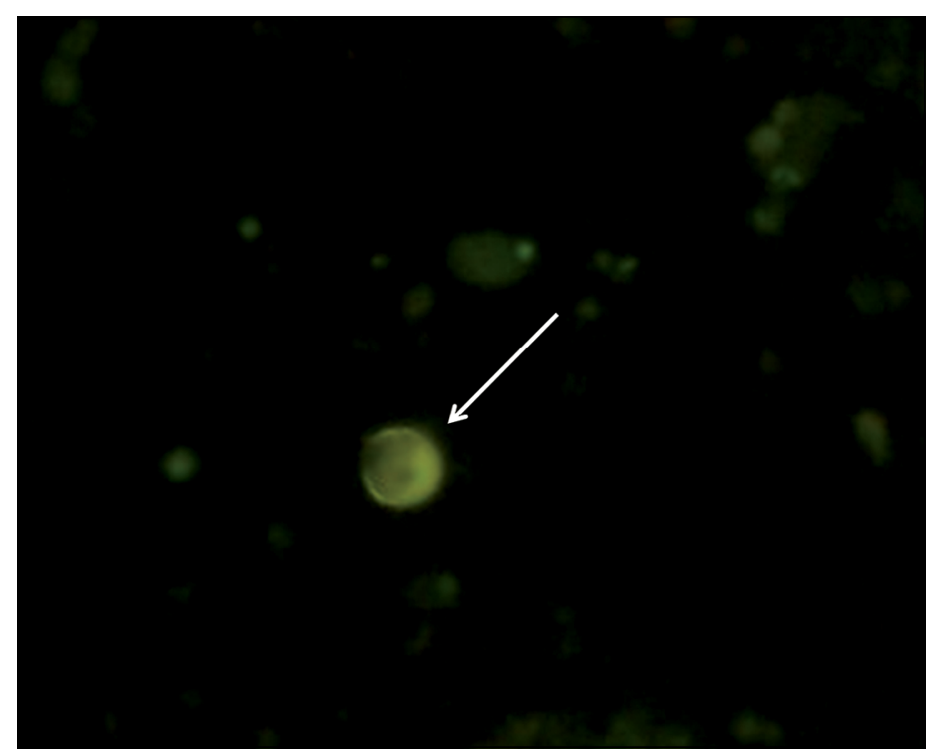

Figura 3. Autofluorescencia de ooquistes en heces bajo microscopio de epifluorescencia (longitud de onda: $490 \mathrm{~nm}$ y $520 \mathrm{~nm}$ ). 


\section{Retrato Microbiológico}

\section{Cyclospora cayetanensis}

Cyclospora cayetanensis es un protozoo intestinal humano, que causa ciclosporiasis (o también ciclosporosis) y pertenece al filo Apicomplexa, subclase Coccidiasina. La infección es endémica en el mundo, principalmente en países tropicales y subtropicales de Latinoamérica y Asia. El coccidio se transmite a través de la ingestión de agua y alimentos contaminados. No se ha descrito la transmisión persona a persona. Una vez que alcanza el intestino delgado, el parásito se multiplica en las células epiteliales provocando atrofia y alteración de las vellosidades. Se produce la liberación de ooquistes inmaduros por las heces, los que se mantienen en el ambiente 7 a 15 días antes de esporular. Los ooquistes maduros son los infectantes y contienen dos esporoquistes ovoidales con dos esporozoitos. Luego de un período de incubación de una a dos semanas, Cyclospora causa diarrea, muchas veces acompañada por anorexia, dolor abdominal, náuseas y vómitos, fatiga, y fiebre baja. La infección generalmente causa molestias gastrointestinales prolongadas, pero autolimitadas (similar a Giardia). En pacientes inmunocomprometidos se puede manifestar en forma crónica y grave (similar a Cryptosporidium).

El diagnóstico parasitológico clásico se basa en la detección de ooquistes redondos $(8-10 \mu \mathrm{m})$ en deposiciones. Hay varias técnicas microscópicas disponibles, pero todas requieren experiencia y son dependientes del operador. Lo más común es el uso de la tinción Ziehl-Neelsen modificada, ej. Kinyoun, recomendada para la detección de Cryptosporidium (Figura 1). Un microscopista entrenado puede detectar ooquistes en un examen parasitológico seriado o en una preparación al fresco por su morfología típica (Figura 2). Una alternativa (menos específica) es el examen de autofluorescencia (Figura 3). La biología molecular ofrece una nueva alternativa diagnóstica, ya que algunos paneles intestinales comerciales incluyen este parásito. El tratamiento de elección es cotrimoxazol.

En 2015 y 2016 se describió un brote en la península de Yucatán en México que causó infecciones en turistas, incluyendo viajeros chilenos. Los cuatro casos detectados en nuestro laboratorio fueron diagnosticados inicialmente por biología molecular (BioFire FilmArray ${ }^{\circledR}$ Gastointestinal Panel, bioMérieux) y confirmados por microscopia.

\section{Referencias bibliográficas}

1.- Ortega Y R, Sanchez R. Update on Cyclospora cayetanensis, a food-borne and waterborne parasite. Clin Microbiol Rev 2010; 23: 21834.

2.- Weitzel T, Neira P, Mehlhorn H. Ciclosporiasis. Apt W, editor. Parasitología Humana. México: McGraw-Hill Interamericana Editores, 2013, pág. 175-8.

3.- Legua P, Seas C. Cystoisospora and Cyclospora. Curr Opin Infect Dis 2013; 26: 479-83.

4.- Chacín-Bonilla L. Epidemiology of Cyclospora cayetanensis: A review focusing in endemic areas. Acta Trop 2010; 115: 181-93.

Thomas Weitzel, Valeska Vollrath, Lorena Porte Laboratorio Clínico, Clínica Alemana de Santiago, Universidad del Desarrollo 